\title{
Intraocular pressure and pupil diameter in healthy cats anesthetized with isoflurane and pre-medicated with isolated acepromazine or in combination with tramadol
}

\author{
[Pressão intraocular e diâmetro pupilar em gatos saudáveis anestesiados com isoflurano e \\ pré-medicados com acepromazina isolada ou em combinação com tramadol] \\ B.E. Rodrigues, A.P. Ribeiro*, T.M. Amorim, A.B. Perotto, \\ M.A. Mendes, L.D. Guimarães
}

Faculdade de Medicina Veterinária - Universidade Federal de Mato Grosso - Cuiabá, MT

\begin{abstract}
The objective of this study was to determine changes on intraocular pressure (IOP) and pupil diameter (PD) in healthy cats anesthetized with isoflurane, and premedicated with acepromazine alone or in combination with tramadol. Thirty cats were allocated in two groups $(\mathrm{n}=15 / \mathrm{each})$ and were treated with acepromazine (AG) or acepromazine/tramadol (ATG). PD and IOP were assessed before and following 30 (PM1), and 40 minutes (PM2) of treatments. Anesthesia was induced with propofol, and IOP and DP were recorded (A10) at 10 minute intervals until the end of anesthesia (A40). IOP decreased in AG and ATG, when comparing baseline with PM1. IOP decreased only in AG, in comparisons between baseline and PM2. During anesthesia, IOP did not change within and between groups. Comparisons between baseline with those recorded at PM1 and 2 showed that PD increased in the ATG. During anesthesia, PD decreased significantly in AG and ATG. Both protocols maintained the IOP within the reference range to perform corneal or intraocular surgery in healthy cats but did not sustain pre-anesthetic pupil dilation observed in ATG.
\end{abstract}

Keywords: rebound tonometry, feline ophthalmology, general anesthesia, mydriasis

\section{RESUMO}

O objetivo do presente artigo é determinar possíveis alterações na pressão intraocular (PIO) e no diâmetro pupilar $(D P)$ em gatos saudáveis anestesiados com isoflurano e pré-medicados com acepromazina isolada ou em combinação com acepromazina/tramadol. Trinta gatos saudáveis foram distribuídos aleatoriamente em dois grupos $(n=15 /$ cada) e tratados com acepromazina $(G A)$ ou acepromazina/tramadol $(G A T)$. DP $e$ PIO foram avaliadas antes (basal) e após 30 (PM1) e 40 minutos (PM2) dos tratamentos. A anestesia foi induzida com propofol, e a PIO e o DP foram registrados (A10) a cada 10 minutos até o final da anestesia com isoflurano (A40). Ao se compararem os valores obtidos no basal com PM1, a PIO diminuiu em GA $e$ GAT; com PM2, a PIO reduziu apenas no GA. Durante a anestesia, a PIO não diferiu dentro e entre os grupos. Comparações entre os valores basais e os registrados em PM1 e em PM2 mostraram que a DP aumentou significativamente no GAT. Durante a anestesia, o DP diminuiu significativamente em GA $e$ GAT. Ambos os protocolos mantêm a PIO dentro dos valores de referência para realizar cirurgias corneanas ou intraoculares em gatos saudáveis, mas não sustentam a dilatação pupilar pré-anestésica observada em GAT.

Palavras-chave: tonometria de rebote, oftalmologia felina, anestesia geral, midríase

\section{INTRODUCTION}

Superficial and penetrating keratectomies are commonly performed in cats with corneal sequestra (Grahan et al., 2017). Although less commonly performed than in dogs, cats can also be subjected to phacoemulsification (Braus et al., 2017). During these procedures, adequate control

Recebido em 30 de junho de 2020

Aceito em 18 de dezembro de 2020

*Autor para correspondência (corresponding author)

E-mail: alexandre.aleribs@gmail.com 
of the pupil diameter (PD) and intraocular pressure (IOP) is critical to the success of the surgery (Gross and Pablo, 2015). A sharp rise in IOP can cause damage to the optic nerve or cause prolapse of the ocular contents in cases of corneal or scleral instability, thus increasing morbidity and worsening prognosis. In patients submitted to corneal or intraocular surgeries, periods of excitement, incoordination, coughing, gagging, or retching are particularly undesirable during the early postoperative period. Therefore, a balanced and multimodal anesthesia with agents capable of producing a smooth anesthetic recovery is desired (Gross and Pablo, 2015; Bellini et al., 2017).

Acepromazine is a phenothiazine widely used in veterinary medicine for its sedative, anti-emetic, anti-arrhythmogenic, and long-acting effects (Cassu et al., 2005; Bellini et al., 2017). Tramadol is a synthetic opioid that has multiple mechanisms of action. In cats, the drug has a relatively high bioavailability and slow clearance when compared to other species (Pypendop and Ilkiw, 2008). The effects of systemic opioid narcotics on the PD vary greatly between species and between classes of mixed and pure opioid agonists (Sharp, 1991). One study has demonstrated that tramadol alone or in association with acepromazine caused significant mydriasis and did not change IOP values in normal cats (Schroder et al., 2018).

It has been reported that all of the available inhalational general anesthetics lower IOP (Gross and Pablo, 2015). Although some species differences may be present, the reduction in IOP after inhalational general anesthetics may be substantial (Bolzan et al., 1998; Ribeiro et al., 2008). Regarding PD, such parameter may vary from marked dilatation to pinpoint with lighter levels of general anesthesia, to progressive mydriasis when inhalational anesthetics are used (Gelatt, 2011; Almeida et al., 2008). For corneal and intraocular surgery, a low normal IOP and large PD are desirable during general anesthesia (Gelatt, 2011). Nonetheless, choosing adequate protocols with these purposes may be challenging, as most analgesic and anesthetic agents change these features (Tamura et al., 2002).

In veterinary medicine, most of the experiments regarding the effects of different sedative/analgesic and anesthetic protocols on the PD and IOP have been conducted in dogs (Douet et al., 2018; Micieli et al., 2018). To date, there are only three studies developed in dogs and performed with balanced protocols, in which IOP values were recorded during the premedication period, after the anesthetic induction, and during the maintenance of anesthesia with an inhalant agent, but PD was not assessed (Bolzan et al., 1998; Tamura et al., 2002; Mayordomo-Feber $e t$ al., 2017).

Only two studies have focused on evaluating ophthalmic parameters in cats treated with analgesic and sedatives (Schroder et al., 2018; Malmasi and Ghaffari, 2015). One reported that intramuscular medetomidine did not cause a statistically significant change in IOP values (Malmasi and Ghaffari, 2015), while in the other, Schroder et al. (2018) reported that tramadol alone or in association with acepromazine caused significant mydriasis that lasted for 120 minutes without changing the IOP values in normal cats. Considering the results published by Schroder $e t$ al. (2018), it seems reasonable to evaluate the behavior of such parameters during general anesthesia, in cats premedicated with the same protocol.

\section{MATERIALS AND METHODS}

Thirty intact male domestic shorthair cats, with an average weight and age of $3.7 \mathrm{~kg}$ (range: 2.5 to $5.8 \mathrm{~kg}$ ) and 1.8 years (range: 1 to 3 years), respectively, were enrolled in this study. Healthy animals were selected if no abnormities were detected on cardiac and respiratory rate, capillary refill time, temperature, skin turgor. Cats with normal eyes were enrolled in the study if no abnormities were detected on the menace, dazzle, direct and indirect pupillary light responses, Schirmer's tear test (Schirmer's Tear Test Strips ${ }^{\circledR}$, Ophthalmos, São Paulo, Brazil), slit-lamp biomicroscopy (SL-15 ${ }^{\circledR}$, Kowa, Japan) of the adnexa, cornea, anterior chamber, lens, and the vitreous. IOP was assessed by rebound tonometry (Tonovet Plus ${ }^{\circledR}$, iCare, Finlândia), the retina and optic nerve were examined by indirect ophthalmoscopy $\left(\mathrm{FOH}-5^{\circledR}\right.$, Eyetec, São Carlos, Brazil), and the corneas should not be positive after the fluorescein dye test (Fluorescein Strips ${ }^{\circledR}$, Ophthalmos, São Paulo, Brazil).

Blood work, basic chemistry profile, and FIV and FelV PCR were also performed. Selected cats were kept in individual cages in a room for two consecutive days, acclimated to the procedures 
and staff, and exposed to a $12 \mathrm{~h}$ of light/dark cycle, fed with dry cat pellets twice daily, and provided with water ad libitum. Only the PD, IOP were assessed in awake animals to determine baseline values. Afterward, the drugs to be used in each group were administered. The animals were allocated randomly to two different groups (15cats/each). In the acepromazine group (AG), cats received $0.05 \mathrm{mg} / \mathrm{kg}$ of acepromazine. In the acepromazine/tramadol group (ATG), a mixture of $0.05 \mathrm{mg} / \mathrm{kg}$ of acepromazine and $3 \mathrm{mg} / \mathrm{kg}$ of tramadol was administered. In all groups, drugs were delivered by intramuscular route.

After the instillation of one drop of $0.5 \%$ proxymetacaine, the horizontal PD and the IOP were assessed bilaterally, with the head positioned horizontally. For PD assessment, an electronic caliper was positioned on the corneal surface at the horizontal margin of the iris (Lee Tools ${ }^{\circledR}$, Xangai, China). The IOP was assessed by means of rebound tonometry (Tonovet Plus ${ }^{\circledR}$, iCare, Finlândia), and the mean of six consecutive measurements was considered for statistical analysis. The experiment was performed in a room with 39 lux luminosity, $42.5 \%$ of relative humidity, and $25^{\circ} \mathrm{C}$ of temperature. Food, but not water, was withheld for 12 hours prior to the experiment.

General anesthesia was induced with intravenous propofol $(5 \mathrm{mg} / \mathrm{kg}$ as needed) until jaw tonus was lost. Afterward, cats were intubated, and anesthesia was maintained with inhaled isoflurane in $100 \%$ oxygen, administered through Baraka system (200ml/kg). Routine anesthetic monitoring was performed using a multiparameter monitor (Cardiocap II $^{\circledR}$, Datex, IL, EUA) and included heart (electrocardiography) and respiratory rates, end-tidal partial pressure of $\mathrm{CO}_{2}$ $\left(\mathrm{EtCO}_{2}\right.$ by capnography) and peripheral oxygen saturation (pulse oximetry). In addition, mean arterial pressure (MAP) was measured using an oscillometer blood pressure device with the cuff being placed on the distal third of the antebrachium.

Following 30 (PM1), and 40 minutes (PM2) of premedication with acepromazine or its association with tramadol, the PD and the IOP were re-assessed as aforementioned, and the subjects were submitted to anesthesia. After anesthetic induction and intubation, cats were positioned in dorsal recumbency. Once the animals had achieved the surgical anesthetic plane (end-tidal isoflurane concentration set at $2.0 \%$ ), the aforementioned parameters were recorded in dorsal recumbency. From this moment (A10) until the end of anesthesia (A40), all parameters were measured in 10-minute intervals. At the end of the experiment, all cats were castrated during the same anesthesia. Cats in the AG received the same dose of tramadol used in ATG, and at the end of the surgical procedures, individuals of both groups received $0.1 \mathrm{~m} / \mathrm{kg}$ of meloxicam subcutaneously.

Measurement of the PD and IOP was performed by the same investigator which was unaware of the treatment protocols throughout the study. In order to minimize the influences of diurnal fluctuation of IOP, in all groups, the experiments were always performed in the morning. All procedures were approved by the Institutional Committee for Ethics in the Use of Animals (protocol 23108.226853/2017-23). Statistical analysis was performed using GraphPad Prism version 8. Data were tested for normal distribution using the Shapiro-Wilk test. For all parameters assessed, comparisons among periods within each group were performed using one way repeatedmeasures analysis of variance (ANOVA), followed by Tukey's multiple comparison test. Two-way ANOVA followed by the Bonferroni adjustment test were used for comparisons between groups. Significance was set at $P<0.05$. Results are shown as mean \pm standard error of mean.

\section{RESULTS AND DISCUSSION}

This was first the study in which the PD and IOP were assessed in premedicated cats subjected to general anesthesia with an inhalant agent. The recommended doses of tramadol and acepromazine for cats range from 2 to $6 \mathrm{mg} / \mathrm{kg}$ and 0.05 to $0.1 \mathrm{mg} / \mathrm{kg}$ respectively. Thus, we chose to use doses close to the lower limits, to minimize the adverse effects of both drugs (Cassu et al., 2005; Bellini et al., 2017).

In our study, baseline values of PD were $7.68 \pm 0.55$ and $7.04 \pm 0.45 \mathrm{~mm}$ in AG and ATG, respectively. These values can be considered normal for the species in an environment with similar luminosity (Amorin et al., 2019) (Figure 1A, Table 1). Similar to what has been previously reported, the combination of acepromazine with 
tramadol induced significant mydriasis in cats, following 30 and 40 minutes of its administration (Schroder et al., 2018). In a previous study, significantly larger PD values were observed as early as 15 minutes after treatment with tramadol alone and following 30 minutes after the combination acepromazine/tramadol (Schroder et al., 2018). In our study, comparisons with baseline showed that PD increased by 1.45 $(\mathrm{P}=0.015)$ and $1.89 \mathrm{~mm}(\mathrm{P}=0.009)$ at $\mathrm{PM} 1$ and 2 respectively, in the ATG. However, PD did not differ significantly when comparing PM1 and 2 within the same group $(\mathrm{P}=0.499)$ (Figure 1A, Table 1).

Some mechanisms may be suggested in order to explain the tramadol-induced mydriasis before the induction of anesthesia in cats of our study. Opiate-induced mydriasis in the cat comes partially from peripheral mechanisms and a large part is centrally mediated (Sharp, 1991). Sharp (1991) observed that separate neural mechanisms control the pupillary components and that $\mu$ opioid receptors are more involved in mediating opiate-induced mydriasis in the cat. Compounds that cause the blockade of noradrenaline reuptake, such as tramadol, are known to stimulate pupil dilatation through the indirect stimulation of $\alpha$ adrenergic receptors and an increase in sympathetic tone (Matouskova et al., 2011).

In the $A G$, the PD values of cats did not change 30 and 40 minutes after premedication $(\mathrm{P}=0.999)$ (Figure 1A, Table 1). Similar results have been reported in cats in which the same treatment protocol was adopted (Schroder et al., 2018). The primary mechanism of acepromazine is the postsynaptic inhibition of the central dopamine and $\alpha-1$ adrenergic receptors (Gross and Pablo, 2015). The blockade of $\alpha-1$ adrenergic receptors by acepromazine, would favor the parasympathetic muscarinic receptors to contract the pupil. Once the postsynaptic inhibition of central dopamine occurs after acepromazine treatment, a significant reduction in $\mathrm{PD}$ is expected (Otto, 2015). Considering such mechanisms, it can be speculated that because cats present a small number of $\alpha-1$ adrenergic receptors in the iris (Stadtbäumer et al., 2006), enlarged PD values were not observed in cats in the AG. After the surgical plane was achieved, the PD decreased significantly in both groups when compared to the awake state $(\mathrm{P}<0.01)$, but differences were not observed between groups (P>0.05) (Figure 1A, Table 1).

It has been reported that PD may vary substantially during general anesthesia (Gelatt, 2011). In the veterinary literature, however, there is only one study conducted in dogs that evaluated the PD during the course of inhalant anesthesia with desflurane (Almeida et al., 2008). In this study, different concentrations of desflurane caused a significant decrease in the PD of dogs after 45 and 60 minutes of anesthesia (Almeida $e t$ al., 2008). After the surgical plane was achieved in the cats of our study, the PD decreased significantly in both groups when compared to time points assessed before the anesthetic procedure. The PD values assessed during the anesthetic procedure can be assumed as miosis, once an average dilation of $2 \mathrm{~mm}$ was observed in both groups from A10 until the end of the experiment.

In our study, baseline values of IOP were $20.33 \pm 1.14$ and $19.10 \pm 0.76 \mathrm{mmHg}$ in $\mathrm{AG}$ and ATG, respectively. These values are within the reference range for the species when a rebound tonometer is used (Rusanen et al., 2010) (Figure 1B, Table 1). Nonetheless, IOP decreased significantly in both the AG $(\mathrm{P}=0.008)$ and ATG $(\mathrm{P}=0.0001)$, when comparing values assessed at the baseline to those assessed at PM1 (Figure 1B, Table 1). In cats treated with acepromazine alone, lower IOP values were also observed at PM2 $(\mathrm{P}=0.021)$ (Figure 1B, Table 1). Differently, a previous study showed that the IOP of cats assessed with applanation tonometry and medicated with acepromazine alone or in association with tramadol did not change throughout 120 of evaluation (Schoroder et al., 2018). Such disparity can be attributed to differences regarding tonometry assessment (rebound vs. applanation), environmental conditions, and the period of acclimation adopted between studies (Schoroder et al., 2018).

Propofol is frequently used for induction of general anesthesia and its effects on IOP in premedicated dogs are controversial (Hasiuk et al., 2014; Webb et al., 2018; Smith et al., 2019). One article described that IOP did not change in premedicated dogs submitted to induction of anesthesia with propofol (Weeb et al., 2018). Other studies described that such parameter increased significantly from orotracheal 
intubation for up until 40 minutes after propofol administration (Hasiuk et al., 2014; Smith et al., 2019). We decided to not evaluate the IOP right after the anesthetic induction with propofol, because intubation usually increases such parameter (Hasiuk et al., 2014; Gross and Pablo, 2015; Smith et al., 2019). Additionally, to evaluate the isolated effect of propofol on IOP, an inhalant agent could not be administered for the maintenance of general anesthesia as it was instituted in the present study. Considering that at least 20 to 30 minutes of evaluation would be required to determine the isolate effect of propofol on IOP, a separate experiment should be performed (Hasiuk et al., 2014; Smith et al., 2019; Webb et al., 2018).

It has been reported that most inhalant anesthetics are considered to reduce the IOP to some extent (Gross and Pablo, 2015. Gellat, 2011). However, some species differences may be present when assessing this parameter in animals anesthetized with these agents (Cullen et al., 1990; Artru and Momota, 1999; Almeida et al., 2004, 2008). In humans, the IOP did not differ significantly from the measurement performed before and after anesthesia with sevoflurane administered at different concentrations (Gofman et al., 2017). In dogs without premedication, sevoflurane and desflurane tended to increase IOP (Almeida et al., 2004, 2008). In dogs premedicated with levomepromazine and anesthetized with halothane, the IOP had decreased by $4.2 \mathrm{mmHg}$ at the end of the anesthetic procedure (Bolzan et al., 1998). In horses, however, halothane had no effect on the IOP (Cullen et al., 1990). In rabbits, various concentrations of sevoflurane up to $3 \%$ did not alter the IOP (Artru and Momota., 1999).

In crested caracaras (bird of prey), both isoflurane and sevoflurane significantly decreased the IOP, but differently from what has been reported in mammals, increased partial pressure of $\mathrm{CO}_{2}$ (assessed by hemogasometry) was negatively correlated with the IOP (Ribeiro et al., 2008). During general anesthesia with isoflurane, an average reduction of 2.85 and $2.06 \mathrm{mmHg}$ in the IOP was observed in AG and ATG, respectively. However, only in cats of AG the IOP achieved significant lower values at $\mathrm{A} 10(\mathrm{P}=0.02)$ and $\mathrm{A} 20$ $(\mathrm{P}=0.04)$ when comparing with values assessed during baseline (Figure 1B, Table 1). Despite the reduction observed in both groups, the IOP values recorded throughout the anesthetic period can be considered normal for the species (Rusanen et al., 2010) (Figure 1B, Table 1).

IOP is influenced by several factors; hypercapnia and hypoxemia induce vasodilatation, which increases intraocular blood volume and is accompanied by an increase in IOP (Gross and Pablo, 2015). Therefore, we aimed to maintain $\mathrm{ETCO}_{2}$ within the limit range for cats (35 to 45 $\mathrm{mmHg}$ ) with an end-tidal isoflurane concentration set at $2.0 \%$. From A10 to A40, IOP was measured with cats positioned in dorsal recumbency, because of the positive relationship between central venous pressure and IOP (Lee et al., 2012. Gross and Pablo, 2015). In addition, cats are usually positioned in dorsal recumbency when corneal and intraocular surgeries are performed (Gellat, 2011).

Regarding the other parameters, despite statistical differences being noticed within and between groups at some time points, the MAP, HR, RR, $\mathrm{ETCO}_{1}$. and $\mathrm{SatO}_{2}$ remained within the reference values for cats anesthetized with isoflurane and premedicated with acepromazine and tramadol (Bellini et al., 2017). One failure of our study was the lack of a crossover design, which could have decreased the variability between groups. However, this was meant as a clinical study; the cats were privately owned animals, and therefore, the study design prohibited assessing the cats twice. 

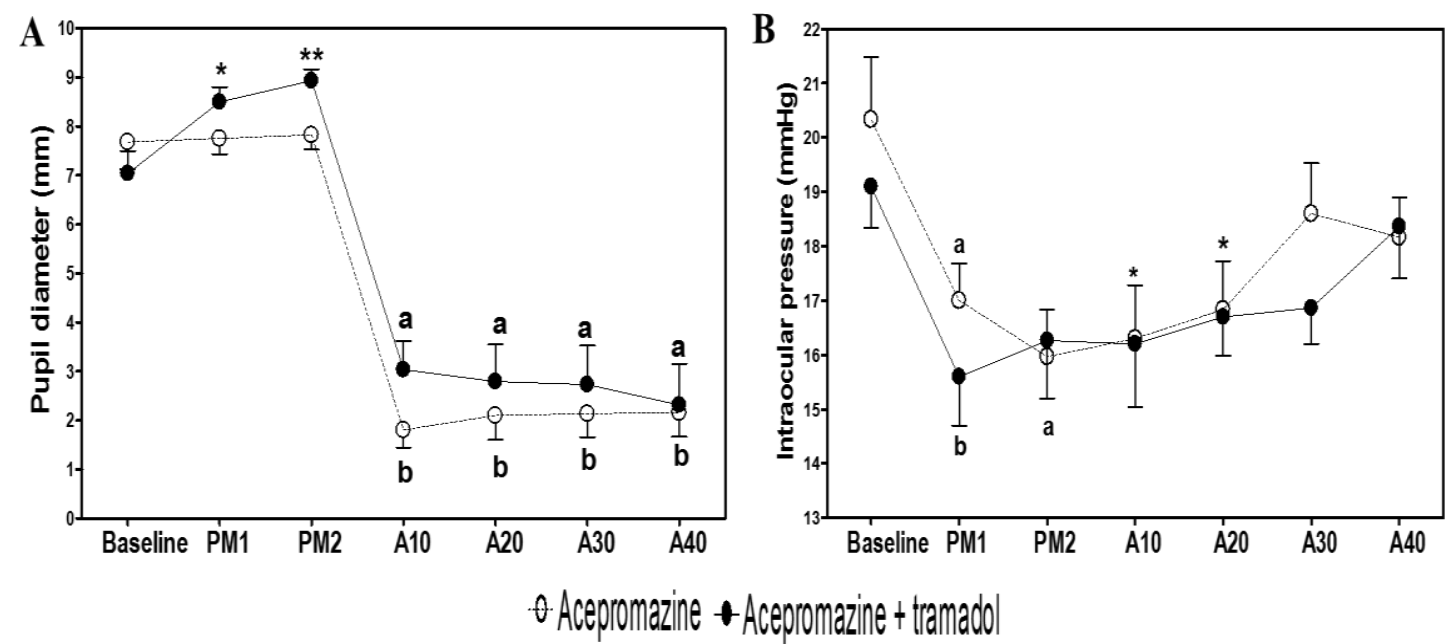

Figure 1. Mean values \pm standard error of pupil diameter $(\mathrm{A})$ and intraocular pressure (B) of cats assessed during baseline and after 30 (PM1), and 40 minutes (PM2) of the administration of acepromazine and acepromazine/tramadol. A10-A40 corresponds to time points assessed during isoflurane anesthesia. A: Increased when compared with baseline of the ATG $(\mathrm{P}=0.015) *,(\mathrm{P}=0.009)^{* *}$. Decreased ${ }^{\mathrm{a}, \mathrm{b}}$ when compared with baseline, PM1 and PM2 within each group $(\mathrm{P}<0.01)$. B: Decreased in $\mathrm{AG}(\mathrm{P}=0.008)^{\mathrm{a}}$ and ATG $(\mathrm{P}=0.0001)^{\mathrm{b}}$ when compared with baseline. *Decreased in AG when compared with baseline $(\mathrm{P}<0.05)$.

Table 1. Mean values \pm standard error of pupil diameter and intraocular pressure of cats assessed during baseline and after 30 (PM1), and 40 minutes (PM2) of the administration of acepromazine (AG) and acepromazine/tramadol (ATG). A10-A40 corresponds to time points assessed during isoflurane anesthesia

\begin{tabular}{lcccc} 
& \multicolumn{2}{c}{ Pupil diameter $(\mathrm{mm})$} & \multicolumn{2}{c}{ Intraocular pressure $(\mathrm{mmHg})$} \\
\cline { 2 - 5 } & $\mathrm{AG}$ & $\mathrm{ATG}$ & $\mathrm{AG}$ & $\mathrm{ATG}$ \\
\hline Baseline & $7.68 \pm 0.55$ & $7.04 \pm 0.45$ & $20.33 \pm 1.14$ & $19.10 \pm 0.76$ \\
PM1 & $7.75 \pm 0.32$ & $8.49 \pm 0.29^{\mathrm{a}}$ & $17.00 \pm 0.68 \mathrm{a}$ & $15.60 \pm 0.89 \mathrm{~b}$ \\
PM2 & $7.82 \pm 0.29$ & $8.93 \pm 0.23^{\mathrm{b}}$ & $15.97 \pm 0.86 \mathrm{a}$ & $16.27 \pm 1.06$ \\
A10 & $1.80 \pm 0.35^{*}$ & $3.03 \pm 0.58^{*}$ & $16.30 \pm 0.98^{*}$ & $16.20 \pm 1.16$ \\
A20 & $1.10 \pm 0.49^{*}$ & $1.79 \pm 0.75^{*}$ & $16.83 \pm 0.89^{*}$ & $16.70 \pm 0.71$ \\
A30 & $1.13 \pm 0.47^{*}$ & $1.73 \pm 0.79^{*}$ & $18.60 \pm 0.92$ & $16.87 \pm 0.66$ \\
A40 & $1.16 \pm 0.49^{*}$ & $1.31 \pm 0.83^{*}$ & $18.17 \pm 0.73$ & $18.37 \pm 0.95$ \\
\hline
\end{tabular}

Pupil diameter: Increased when compared with baseline of the ATG $(\mathrm{P}=0.015)^{\mathrm{a}},(\mathrm{P}=0.009)^{\mathrm{b}}$. * Decreased when compared with baseline, $\mathrm{PM} 1$ and $\mathrm{PM} 2$ within each group $(\mathrm{P}<0.01)$.

Intraocular pressure: Decreased in $\mathrm{AG}(\mathrm{P}=0.008)^{\mathrm{a}}$ and $\mathrm{ATG}(\mathrm{P}=0.0001)^{\mathrm{b}}$ when compared with baseline. *Decreased in AG when compared with baseline $(\mathrm{P}<0.05)$.

\section{CONCLUSION}

Animals of the acepromazine/tramadol group had higher values of PD throughout the experiment than those that received acepromazine alone. However, this parameter was not maintained throughout the anesthetic period and could not inhibit the occurrence of miosis. From our results, authors suggest that the combination of acepromazine/tramadol can be used as premedication in cats anesthetized with isoflurane to perform corneal or intraocular surgeries, once this protocol maintains IOP stable and within the reference range for this species. If surgical mydriasis is necessary, instillation of parasympatholytics, sub-tenon anesthesia, or intracameral injection of epinephrine should be instituted.

\section{ACKNOWLEDGMENTS}

The authors would like to thank CAPES for the scholarship provided. 


\section{REFERENCES}

ALMEIDA, D.E.; NISHIMORI, C.T.; ORIÁ A.P. et al. Effects of nitrous oxide on IOP and pupillary diameter in dogs anesthetized with varying concentrations of desflurane. Vet. Ophthalmol., v. 11, p.170-176, 2008.

ALMEIDA, D.E.; REZENDE, M.L.; NUNES, N. et al. Evaluation of intraocular pressure in association with cardiovascular parameters in normocapnic dogs anesthetized with sevoflurane and desflurane. Vet. Ophthalmol., v.7, p.265-269, 2004.

AMORIM, T.M.; DOWER, N.M.B.; STOCCO, M.B. et al. Effects of intracameral injection of epinephrine and $2 \%$ lidocaine on pupil diameter, intraocular pressure, and cardiovascular parameters in healthy cats. Vet. Ophthalmol., v.21, p.276-283, 2019.

ARTRU, A.A.; MOMOTA, Y. Trabecular outflow facility and formation rate of aqueous humor during anesthesia with sevoflurane-nitrous oxide or sevoflurane-remifentanil in rabbits. Anesth. Analg., v.88, p.781-786, 1999.

BELLINI, L.; MOLLO, A.; CONTIERO, B. et al. Intraoperative end-tidal concentration of isoflurane in cats undergoing ovariectomy that received tramadol, buprenorphine or a combination of both. J. Feline Med. Surg., v.19, p.110-116, 2017.

BOLZAN, A.A.; LAUS, J.L.; NUNES, N. et al. Effects of metaraminol bitartrate on intraocular pressure in dogs under halothane anesthesia. Vet. Ophthalmol., v.1, p.115-118, 1998.

BRAUS, B.K.; TICHY, A.; FEATHERSTONE, $\mathrm{H}$. et al. Outcome of phacoemulsification following corneal and lens laceration in cats and dogs (2000-2010). Vet. Ophthalmol., v.20, p.4-10, 2017.

CASSU, R.N.; CORDEIRO, M.O.; RODENAS, E. Avaliação do efeito sedativo e da dose de indução anestésica do propofol sob diferentes medicações pré-anestésicas em gatos. Rev. Clín. Vet., v.10, p.68-76, 2005.

CULLEN, L.K.; STEFFEY, E.P.; BAILEY, C.S. et al. Effect of high $\mathrm{PaCO}_{2}$ and time on cerebrospinal fluid and intraocular pressure in halothane-anesthetized horses. Am. J. Vet. Res., v.51, p.300-304, 1990.
DOUET, J.Y.; REGNIER, A.; DONGAY, A. et al. Effect of sedation with butorphanol on variables pertaining to the ophthalmic examination in dogs. Vet. Ophthalmol., v.21, p.452-458, 2018.

GELATT, K.N. Anesthesia for ophthalmic surgery. In: _. Veterinary ophthalmic surgery. 5.ed. Oxford: Elsevier, 2011. p.37-50.

GOFMAN N.; COHEN B.; MATOT I. et al. Do intraocular pressure measurements under anesthesia reflect the awake condition? $J$. Glaucoma, v.26, p.299-302, 2017.

GRAHAN, K.L.; WHITE, J.D.; BILLSON, F.M. Feline corneal sequestra: outcome of corneoconjunctival transposition in 97 cats (109 eyes). J. Feline Med. Surg., v.19, p.710-716, 2017.

GROSS, M.E.; PABLO, L.S. Ophthalmic patients. In: GRIMM, K.A.; LEIGH, L.A.; TRANQUILLI, W.J. et al. Veterinary anesthesia and analgesia. 5.ed. Iowa: Roca, 2015. p.963992.

HASIUK, M.M.; FORDE, N.; COOKE, A. et al. A comparison of alfaxalone and propofol on intraocular pressure in healthy dogs. Vet Ophthalmol., v.17, p.411-416, 2014.

LEE, J.Y.; YOO, C.; JUNG, J.H. et al. The effect of lateral decubitus position on intraocular pressure in healthy young subjects. Acta Ophthalmol., v.90, p.68-71, 2012.

MALMASI, A.; GHAFFARI, M.S. Lack of effects of intramuscular medetomidine on intraocular pressure in clinically normal cats. $J$. Feline Med. Surg., v.18, p.315-317, 2015.

MATOUSKOVA, O.; SLANAR, O.; CHYTIL, L. et al. Pupillometry in healthy volunteers as biomarker of tramadol efficacy. J. Clin. Pharm. Ther., v.36, p.513-517, 2011.

MAYORDOMO-FEBER, A.; RUBIO, M.; GASSENT-MARTÍNEZ, M. et al. Effects of morphine-alfaloxone-midazolam premedication, alfalaxone induction and sevoflurane maintenance on intraocular pressure and tear production in dogs. Vet. Rec., v.180, p.474-478, 2017. 
MICIELI, F.; CHIAVACCINI, L.; LAMAGNA, B. et al. Comparison of intraocular pressure and pupil diameter after sedation with either acepromazine or dexmedetomidine in healthy dogs. Vet. Anaesth. Analg., v.45, p.667-671, 2018.

OTTO K. A. Physiology, pathophysiology, and anesthetic management of patients with neurologic disease. In: GRIMM, K.A.; LEIGH, L.A.; TRANQUILLI, W.J. et al. Veterinary anesthesia and analgesia. 5.ed. Iowa: Roca, 2015. p.559-583.

PYPENDOP, B.H.; ILKIW, J.E. Pharmacokinetics of tramadol, and its metabolite O-desmethyl-tramadol, in cats. J. Vet. Pharmacol. Ther., v.31, p.52-59, 2008.

RIBEIRO, A.P.; VITALINO, S.N.; THIEASEN, R. et al. Intraocular pressure and its correlation with blood gas parameters in crested caracaras (Caracara plancus) anesthetized with isoflurane and sevoflurane. Braz. J. Vet. Res. Anim. Sci., v.60, p.1461-1467, 2008.

RUSANEN, E.; FLORIN, M.; HÄSSIG, M. Evaluation of a rebound tonometer (tonovet) in clinically normal cat eyes. Vet. Ophthalmol., v.13, p.31-36, 2010.

SCHRODER, D.C.; MONTEIRO, B.G.; PYTLAK, D.B. et al. Effects of tramadol and acepromazine on intraocular pressure and pupil diameter in young healthy cats. Cienc. Rural, v.48, p.e20170071, 2018.
SHARP, L.G. Separate neural mechanisms mediate sufentanil-induced pupillary responses in the cat. J. Pharmacol. Exp. Ther., v.256, p.845849, 1991.

SMITH, M.D.; BARLETTA, M.; DIEHL, K.A. et $a l$. Effect of propofol and ketamine-diazepam on intraocular pressure in healthy premedicated dogs. Vet. Anaesth. Analg., v.46, p.36-42, 2019.

STADTBÄUMER, K.; FROMMLET, F.; NELL, B. Effects of mydriatics on intraocular pressure and pupil size in the normal feline eye. Vet. Ophthalmol., v.9, p.233-237, 2006.

TAMURA, E.Y.; BARROS, P.S.M.; CORTOPASSI, S.R.G. et al. Effects of two preanesthetic regimens for ophthalmic surgery on intraocular pressure and cardiovascular measurements in dogs. Vet. Ther., v.3, p.81-87, 2002.

WEBB, T.R.; WYMAN, M.; SMITH, J.A. et al. Effects of propofol on intraocular pressure in premedicated and nonpremedicated dogs with and without glaucoma. J. Am. Vet. Med. Assoc., v.252, p.823-829, 2018. 